\title{
Sodium Iodide Symporter (NIS) and Thyroid
}

\author{
Christine Spitzweg ${ }^{1}$, John C. Morris ${ }^{2}$ \\ Department of Internal Medicine II, Klinikum Grosshadern, Ludwig-Maximilians-University Munich, Germany ${ }^{1}$, and \\ Division of Endocrinology, Mayo Clinic \& Medical School, 200 First Street, Rochester, MN 55905, USA ${ }^{2}$
}

\section{INTRODUCTION}

Active transport of iodide into the thyroid gland is a crucial and rate-limiting step in the biosynthesis of thyroid hormones which play an important role in the metabolism, growth and maturation of a variety of organ systems, in particular the nervous system ${ }^{1}$. Although, iodide transport into the thyroid gland has been known for decades to be mediated by a specific sodium-dependent iodide transporter located at the basolateral membrane of thyroid follicular cells, the sodium iodide symporter (NIS) gene was cloned only five years ago ${ }^{2,3}$. NIS co-transports two sodium ions along with one iodide ion, with the transmembrane sodium gradient serving as the driving force for iodide uptake. This sodium gradient, providing the energy for this transfer, is generated by the ouabain-sensitive $\mathrm{Na}+/ \mathrm{K}+-A T P a s e$. NIS-mediated iodide transport is therefore inhibited by the $\mathrm{Na}+/ \mathrm{K}+-$ ATPase inhibitor ouabain as well as by the competitive inhibitors thiocyanate and perchlorate ${ }^{1}$. Following active transport across the basolateral membrane, iodide is translocated across the apical membrane by pendrin, the PDS gene product, which is a chloride/iodide transport$\mathrm{er}^{4-8}$ (Figure 1). Iodide is then organified in a complex reaction including oxidation catalyzed by thyroid perox-

Key-words: Sodium Iodide Symporter, Sodium iodide symporter gene, thyroid

Address Correspondence to:

John C. Morris, M.D., Division of Endocrinology, Mayo Clinic \& Medical School, 200 First Street, Rochester, MN 55905, Phone:

507-284-2324, Fax: 507-284-4521,

e-mail:morris.john@mayo.edu

Received 12-10-2001, Accepted 18-11-2001 idase (TPO) and incorporation into tyrosyl residues along the thyroglobulin $(\mathrm{Tg})$ backbone. The thyroid hormones T3 and T4 are synthesized by coupling of two iodotyrosine residues and stored in the colloid. All of these steps are stimulated by pituitary-derived thyroid stimulating hormone (TSH), which interacts with the TSH receptor at the basolateral membrane of thyroidal cells, through the cAMP pathway (Figure 1) ${ }^{1}$.

In addition to its key role in thyroid physiology, NIS and NIS-mediated iodide accumulation in the thyroid gland represent crucial prerequisites for diagnostic scintigraphic imaging as well as for the highly efficient radioiodine therapy of benign and malignant thyroid diseases. Cloning of the NIS gene in 1996 by N. Carrasco's group $^{2}$ represented a major breakthrough in the study of thyroidal iodide transport, and allowed investigation of NIS-related thyroid disorders, including autoimmune thyroid disease and NIS gene mutations, as well as possible therapeutic applications of NIS, which will be summarized in the present article.

\section{Molecular characterization and regulation of NIS}

Cloning and sequencing of the rat sodium iodide symporter (rNIS) from a Fisher rat thyroid line (FRTL-5)derived cDNA library ${ }^{2}$ revealed a protein of 618 amino acids which is highly homologous ( $87 \%$ identity) to the subsequently cloned human sodium iodide symporter (hNIS) $)^{3}$. The human NIS gene is localized on chromosome 19p12-13.2 and encodes a glycoprotein of 643 amino acids with a molecular mass of approximately 70-90 $\mathrm{kDa}$. The coding region of hNIS contains 15 exons interrupted by 14 introns and codes for a $3.9 \mathrm{~kb} \mathrm{mRNA}^{9}$. As a member of the sodium-dependent transporter family, NIS represents an intrinsic membrane protein with 13 


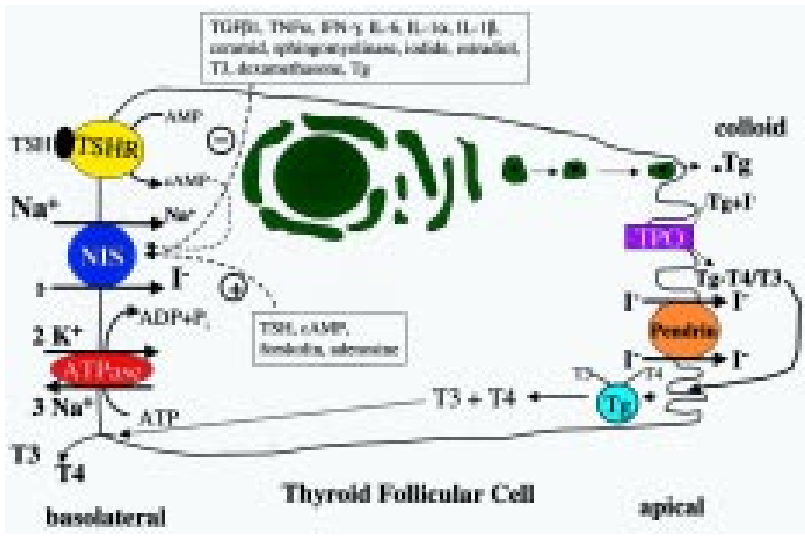

Figure 1. Schematic illustration of a thyroid follicular cell showing the key aspects of thyroid iodine transport and thyroid hormone synthesis. TSHR $=$ TSH - receptor, NIS = sodium iodide symporter, $\mathrm{TPO}=$ thyroid peroxidase, $\mathrm{Tg}=$ thyroglobulin, $\mathrm{T} 3=$ triiodothyronine, $\mathrm{T} 4=$ thyroxine.

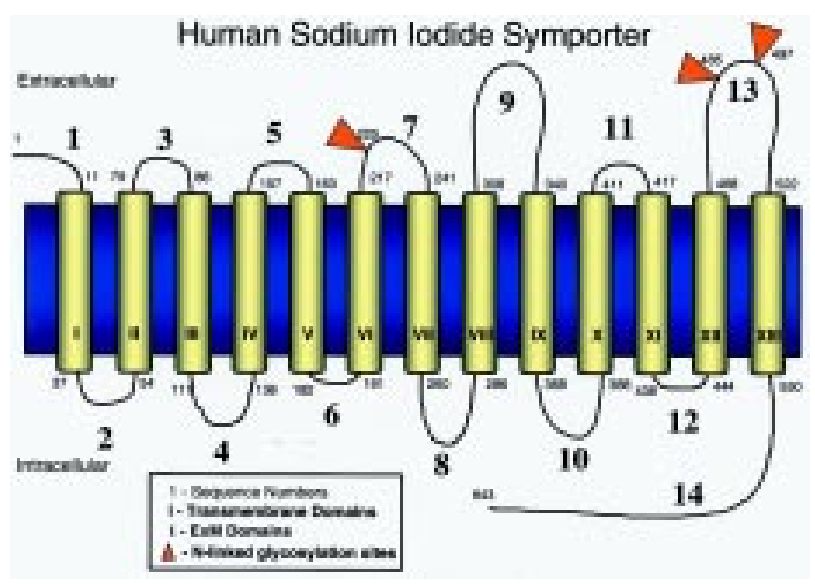

Figure 2. Schematic model of the human sodium iodide symporter representing an intrinsic membrane protein with 13 transmembrane domains.

putative transmembrane domains, an extracellular amino-terminus and an intracellular carboxyl-terminus (Figure 2). The NIS protein has three potential N-linked glycosylation sites, one being located in the fourth and two are in the last extracellular loop ${ }^{10}$.

Pituitary-derived TSH had been known for decades to stimulate iodide transport into the thyroid gland via the adenylate cyclase cAMP pathway ${ }^{1}$. After cloning of NIS, several studies in vivo in rats as well as in vitro in FRTL-5 cells and cultured human thyroid cells showed that treatment with TSH stimulates iodide transport activity, as well as NIS gene and protein expression ${ }^{11-14}$. Forskolin and $(\mathrm{Bu}) 2 \mathrm{cAMP}$ are capable of mimicking this stimulatory effect on both iodide transport activity as well as NIS gene and protein expression, suggesting that TSH regulates NIS expression through the cAMP signal transduction pathway ${ }^{11}$. A more recent study by C. Riedel et al. showed that TSH not only stimulates NIS transcription and biosynthesis, but also includes evidence for posttranscriptional regulation of NIS function by TSH. The authors show for the first time that NIS is a phosphoprotein whose phosphorylation pattern is regulated by $\mathrm{TSH}^{15}$. They further demonstrate that TSH is required for targeting of NIS to the plasma membrane. In the absence of TSH NIS is redistributed from the plasma membrane to intracellular compartments, and therefore loses its ability to transport iodide across the plasma membrane ${ }^{15}$.

Furthermore, adenosine, which acts as an autocrine factor in FRTL-5 cells and potentiates TSH-induced $\mathrm{H}_{2} \mathrm{O}_{2}$ production, an essential step for thyroid hormone synthesis, has been reported to stimulate NIS mRNA and protein expression, as well as iodide transport, in FRTL5 cells $^{16}$ (Figure 1 ).

In addition to agents stimulating NIS expression and function, several inhibitors of NIS expression have been identified (Figure 1). Transforming growth factor-1 $\beta$, a potent inhibitor of growth and DNA synthesis in thyroid cells, has been found to suppress TSH-induced NIS mRNA and protein levels, as well as TSH-stimulated iodide uptake activity in FRTL-5 cells ${ }^{17}$. Further, ceramide and sphingomyelinase, which play important roles in the nonthyroidal illness syndrome and in age-associated hypothyroidism, have been shown to downregulate NIS mRNA expression in FRTL-5 cells ${ }^{18}$. Moreover, TNF- $\alpha$, IFN $\gamma$ and IL- $1 \alpha$ inhibited NIS mRNA expression and iodide uptake activity in FRTL-5 and human thyroid cells ${ }^{18-21}$. IL-1 $\beta$ and IL- 6 decreased NIS mRNA expression in FRTL-5 cells, with IL-1 $\beta$ also having an inhibitory effect on iodide accumulating activity ${ }^{21}$. Thus, suppression of NIS gene expression and function by certain cytokines may be responsible, at least in part, for development of hypothyroidism and impaired radioiodine uptake by thyroid tissue in autoimmune hypothyroidism, especially in the early stages of Hashimoto's thyroiditis.

Exposure to T3 and dexamethasone suppressed iodide accumulation, and expression of NIS mRNA and protein in FRTL-5 cells ${ }^{21}$. If this in vitro effect of dexamethasone can be confirmed in vivo, it might, at least in part, explain the therapeutic benefit of corticosteroids in the treatment of amiodarone-induced thyroiditis type II, which involves iodine-induced damage to thyroid fol- 
licles $^{21}$. Physiologic concentrations of Tg suppress TSHinduced NIS promoter activity, NIS protein and mRNA levels in vitro, as well as iodide uptake activity in vitro and in vivo. Tg-mediated suppression of NIS expression may represent a negative feedback autoregulatory mechanism that counterbalances TSH stimulation of follicular function ${ }^{22}$. Recently, estradiol has been shown to increase proliferation and decrease NIS mRNA expression in FRTL-5 cells, suggesting that downregulation of NIS expression and function by estradiol may contribute to the higher prevalence of goiter in women ${ }^{23}$ (Figure 1).

Cloning of NIS allowed investigation of its role in the escape from the acute Wolff-Chaikoff effect. Organic binding of iodide within the thyroid gland was reported to be blocked in the presence of elevated plasma iodide levels by Wolff and Chaikoff in $1948^{24}$. This acute WolffChaikoff effect was demonstrated to be transient, as the thyroid gland adapted to prolonged iodide excess, resuming near-normal hormone synthesis, which is known as the escape from the acute Wolff-Chaikoff effect ${ }^{25}$. In addition, low doses of potassium iodide resulted in decreased cell proliferation and diminished TPO and NIS mRNA expression in hyperplastic dog thyroid glands treated with goitrogens and deprived of iodide, whereas $\mathrm{Tg}$ and TSHR mRNA expression was not altered ${ }^{26}$. Potassium iodide treatment also suppressed NIS mRNA levels and iodide accumulating activity in FRTL-5 cells ${ }^{21}$. In support of these data, a recent study in rats showed suppression of thyroidal NIS mRNA and protein levels after iodide administration in vivo ${ }^{27}$. Collectively, these data suggest that the escape from the acute WolffChaikoff effect is caused by down-regulation of NIS, resulting in decreased levels of intrathyroidal iodine, thereby allowing iodide organification to resume (Figure 1).

\section{Expression of the sodium iodide symporter in benign and malignant thyroid tissue}

Cloning of the NIS gene and availability of polyclonal and monoclonal hNIS specific antibodies assist investigation of NIS expression patterns in various benign and malignant thyroid tissues ${ }^{12,28-32}$. While normal thyroid tissue reveals heterogenous NIS protein expression at the basolateral membrane of a minority of follicular cells ${ }^{28,31}$, Graves' thyroid tissue reveals strong NIS protein expression confined to the basolateral aspect of most thyroid follicular cells, which is consistent with the clinical observation of diffusely increased radioiodine uptake in acute Graves' thyrotoxicosis ${ }^{12,28,31,33}$. As demonstrated by Northern and Western blot analysis, NIS mRNA and protein expression is increased about 3- to 4-fold in Graves' thyroid tissue ${ }^{12}$. Given stimulation of iodide trans- port as well as NIS gene and protein expression in thyroid follicular cells by TSH through activation of the cAMP pathway, increased levels of NIS mRNA and protein in Graves' thyroid tissue are considered to reflect increased cAMP accumulation induced by elevated levels of TSH-receptor stimulating antibodies in Graves' disease $^{12}$. The pattern of NIS protein expression in autoimmune thyroiditis has been shown to be similar to normal thyroid tissue with strongest NIS expression in cells close to lymphocytic infiltrates, perhaps supporting the concept of NIS as an autoantigen that may attract cytotoxic lymphocytes during the evolution of autoimmune thyroiditis ${ }^{28}$. Toxic multinodular goiters also reveal heterogenous NIS protein expression which appears to be stronger than in normal thyroid gland ${ }^{28}$. Further, NIS mRNA levels have been shown to be low in nontoxic multinodular goiter and diffuse iodine deficiency goit$\mathrm{er}^{33}$. While NIS mRNA and protein expression levels are increased in autonomously functioning thyroid nodules with increased radioiodine uptake, they are decreased in cold thyroid nodules with low or absent radioiodine uptake $^{33}$. In addition, using a quantitative RT-PCR assay, NIS mRNA levels have been demonstrated to be correlated with TTF-1 and Pax-8 gene expression in Graves' disease and, to a lesser degree, in autonomously functioning thyroid nodules, nontoxic multinodular goiter and diffuse iodine deficiency goiter ${ }^{33}$. Increased thyroidal NIS expression levels and iodide accumulation activity in Graves' disease and autonomously functioning thyroid nodules allows effective therapeutic application of radioiodine in these benign thyroid disorders.

Thyroidal NIS expression further opens the door to effective thyroid cancer therapy given the accumulation of sufficient amounts of radioiodine in the tumor ${ }^{34,35}$. Since cloning of the NIS gene, many studies have investigated the molecular mechanisms underlying decreased levels of radioiodine accumulation in thyroid cancer tissues and their metastases that limit the therapeutic efficacy of ${ }^{131}$ I. Smanik et al. reported a much lower level of NIS mRNA expression in thyroid carcinoma tissues (2 papillary, 1 follicular, 1 anaplastic) compared to normal thyroid tissue using Northern blot analysis. Using RTPCR the same authors found variable levels of NIS expression in a panel of different papillary carcinoma tissues which is consistent with the clinical observation of variable response of papillary carcinoma to radioiodine treatment ${ }^{9}$. Further, using RT-PCR no NIS mRNA expression was detected in five different human thyroid carcinoma cell lines that have lost iodide uptake activi$t^{3}$. In another series of thyroid carcinomas (19 papillary, 5 follicular, 2 anaplastic) Arturi et al. used RT-PCR 
to detect loss of NIS mRNA expression in 5 of 19 papillary cancers, 1 of 5 follicular cancers and both anaplastic cancers $^{29}$. In a more recent study using a kinetic quantitative RT-PCR method, NIS mRNA expression was shown to be decreased in 40 of 43 thyroid carcinomas (38 papillary, 5 follicular) and in 20 of 24 cold adenomas as compared to normal thyroid tissue, whereas NIS mRNA levels were increased in each of 8 toxic adenomas and 5 Graves' thyroid tissues. In thyroid cancer tissues, a positive correlation was found between the expression levels of NIS, TPO, Tg and TSH receptor, and higher tumor stages were associated with lower levels of NIS expression ${ }^{36}$. Park et al. investigated NIS mRNA levels in 23 papillary carcinomas and 7 pairs of primary and lymph node metastatic tissues by RT-PCR and RNase protection assay. Three of 23 papillary carcinomas did not express NIS mRNA and the rest showed variable levels of NIS mRNA expression which were lower than in normal thyroid tissue. In spite of NIS expression in the primary tumor, 2 of 6 lymph node metastases did not express NIS mRNA. Levels of NIS mRNA expression in the remaining 4 lymph node metastases were lower than those in the primary tumors. One sample of lymph node metastatic tissue showed significant NIS mRNA expression while no NIS mRNA was detected in the primary tumor. Therefore, since no correlation was found between NIS mRNA expression levels in primary and lymph node metastatic tissue, measurement of NIS mRNA expression levels in primary tissue cannot predict the therapeutic response to ${ }^{131} \mathrm{I}$ in the metastatic tissue ${ }^{37}$. Further, NIS mRNA expression levels have been shown to be decreased in oncogene-transformed $\mathrm{PC} \mathrm{Cl} 3$ rat thyroid cell lines (PC v-erbA, PC HaMSV, PC v-raf and PC E1A), and were almost completely absent in PC RET/ PTC, PC KiMSV, PC p53143ala and PC PyMLV. These data suggest that oncogene activation may be involved in the pathophysiology of reduced NIS expression in thyroid cancer ${ }^{38}$.

Using specific polyclonal and monoclonal anti-hNIS antibodies NIS protein expression levels in various malignant thyroid tissues have been investigated. In contrast to normal thyroid tissue, most studies showed decreased levels of NIS protein expression with less pronounced basolateral orientation in malignant thyroid tumors $^{28,30,31,39}$. Jhiang et al. reported no NIS protein expression in 3 papillary carcinomas and 1 follicular carcinoma using a rabbit polyclonal hNIS-specific antibody $(\text { aa } 468-643)^{39}$. No NIS protein expression was detected in anaplastic and Hurthle cell carcinomas ${ }^{30,31}$. Using a rabbit polyclonal hNIS-specific antibody (aa 615-643) immunohistochemical analysis of 5 follicular and 9 pap- illary carcinomas revealed low or absent NIS protein expression, with NIS protein expression levels correlating with differentiation levels ${ }^{28}$. Interestingly, the number of TSH receptor positive cells was also decreased in thyroid carcinomas which may, at least in part, explain decreased levels of NIS expression and iodide concentrating capacity in thyroid carcinomas, given TSH as an important stimulator of NIS gene and protein expression. In a limited number of cases, comparison of iodide uptake on radioiodine scans and NIS expression patterns in thyroid carcinomas and metastases revealed a positive correlation suggesting that NIS expression levels might predict the therapeutic efficacy of radioiodine therapy in thyroid cancer $^{28}$. Evaluation of the relationship between NIS protein expression in primary or lymph node lesions and ${ }^{131} \mathrm{I}$ uptake in recurrent lesions of differentiated thyroid cancer ( 5 follicular, 62 papillary) showed that NIS immunohistochemical staining predicted ${ }^{131} \mathrm{I}$ uptake in recurrent cancer with a $100 \%$ positive predictive value and a $46.2 \%$ negative predictive value. Patients with positive NIS immunostaining responded better to ${ }^{131}$ I therapy than patients with negative NIS immunostaining ${ }^{40}$. In a very recent study M. R. Castro et al. determined if NIS protein expression in primary differentiated thyroid tumors correlates with subsequent radioiodine uptake in metastatic lesions. Thyroid tissue specimens from 60 patients with metastatic thyroid cancer, who had undergone total or near-total thyroidectomy for differentiated thyroid cancer, were subjected to immunostaining using a mouse monoclonal hNIS-specific antibody. For each patient correlation between immunostaining results and whole body scan after thyroid hormone withdrawal was analyzed. Positive immunostaining accurately predicted a positive whole body scan in $84 \%$, the ability of immunostaining to detect cases with a positive scan was $86 \%$, and increased to $90 \%$ when patients receiving thyroid hormone therapy at the time of surgery were excluded. These results suggest that NIS immunostaining of the thyroidal primary tumor in patients with differentiated thyroid cancer has the potential to predict the iodide accumulating behavior of subsequent deposits of metastatic and recurrent cancer, and might therefore be useful in the management of patients with known or suspected thyroid cancer ${ }^{41}$.

The studies summarized above suggest that reduction in NIS expression may account, at least in part, for the reduced iodide uptake activity generally observed in thyroid cancer tissue. NIS gene mutations could not be found in differentiated human thyroid carcinomas (5 papillary, 2 follicular) with reduced iodide accumulating activity $^{42}$. Confirmation of these data in a larger series of 
thyroid cancer samples is needed to rule out mutations in the NIS gene as cause of impaired iodide uptake activity. Kogai et al. who studied the regulation of the NIS gene in human papillary thyroid cancer cell lines with low levels of NIS gene expression and iodide uptake activity, and primary human thyroid cells, identified a region in the NIS gene 5'-flanking region, -596 to -268 , which is essential to confer full promoter activity in primary human thyroid cells. NIS promoter activity was markedly reduced in the human papillary thyroid cancer cell lines, which might be due to decreased expression of potential novel nuclear factors in these cell lines ${ }^{43}$.

In contrast to these data, Northern blot and immunoblot analysis as well as immunohistochemical staining of 31 papillary carcinomas by Saito et al. using a rabbit polyclonal hNIS-specific antibody (aa 466-522) showed elevated NIS expression levels in approximately $50 \%$ of the tumors ${ }^{32}$. In a more recent study Dohan O. et al. analyzed NIS protein expression in 57 thyroid cancer samples by immunohistochemistry, and showed increased NIS protein expression levels in as many as $70 \%$ of the tissue samples. In addition, NIS was localized not only in the plasma membrane, but also to a great extent in intracellular compartments. These data suggest that malignant transformation in thyroid cancer cells interferes either with proper targeting of NIS to the plasma membrane, or with mechanisms retaining NIS in the plasma membrane, thereby explaining reduced iodide accumulation levels in spite of increased NIS expression levels in a subset of thyroid cancer samples ${ }^{44}$. Promoting NIS targeting to the plasma membrane therefore represents one of the major therapeutic aims to improve therapeutic efficacy of ${ }^{131} \mathrm{I}$ in thyroid tumors with reduced iodide accumulation capacity in the presence of increased intracellular NIS expression levels.

In contrast, therapeutic strategies that enhance functional NIS expression are needed in thyroid tumors with reduced NIS expression levels to restore their susceptibility to radioiodine treatment. For example, retinoic acid, a well characterized reagent with differentiationinducing properties, has been shown to suppress iodide uptake and NIS mRNA levels in normal, non-transformed FRTL-5 cells, whereas NIS mRNA expression levels were up-regulated in human follicular thyroid carcinoma cell lines in vitro ${ }^{45}$. A clinical study in 20 patients with advanced thyroid cancer ( 8 follicular, 7 papillary, 5 oxyphilic) showed that 13-cis-retinoic acid treatment (1.5 $\mathrm{mg} / \mathrm{kg} /$ day for 5 weeks) was capable of reinducing iodine uptake in $50 \%$ of tumors ${ }^{46}$. Treatment with retinoic acid may therefore provide a means of re-establishing the ther- apeutic efficacy of radioiodine therapy by targeted upregulation of iodide transport in thyroid cancer cells while down-regulating iodide accumulation in surrounding normal thyroid tissue. Another study suggests that DNA methylation may be involved in loss of functional NIS expression in thyroid cancer. Analysis of NIS mRNA expression in 23 thyroid cancer samples showed correlation of loss of NIS expression with loss of clinical radioiodine uptake. However, some of the thyroid carcinoma samples with NIS expression did not concentrate iodide suggesting additional post-transcriptional mechanisms for loss of NIS function. In 7 human thyroid carcinoma cell lines without NIS mRNA expression, demethylation treatment with 5-azacytidine or sodium butyrate restored NIS mRNA expression in 4 cell lines and iodide uptake in 2 cell lines. Investigation of methylation patterns in these cell lines revealed that successful restoration of NIS transcription was associated with demethylation of NIS DNA in the untranslated region within the first exon. These data suggest a role of DNA methylation in loss of NIS expression and function in thyroid carcinomas as well as a potential application for chemical demethylation therapy in restoring responsiveness to ${ }^{131} \mathrm{I}^{47}$. A very recent study showed that the novel histone deacetylase inhibitor, depsipeptide (FR901228), is capable of increasing NIS mRNA levels as well as iodide accumulating activity in poorly differentiated thyroid carcinoma cell lines. If these results can be confirmed in vivo, depsipeptide might be used clinically in dedifferentiated thyroid carcinomas as an adjunct to radioiodine therapy ${ }^{48}$.

\section{NIS gene mutations}

Iodide transport defects resulting in congenital hypothyroidism are suggestive of a defective NIS molecule due to NIS gene mutations. Diagnostic criteria for an iodide transport defect are: 1) goiter with hypothyroidism or compensated hypothyroidism, 2) little if any uptake of radioiodine, 3) no concentration of iodide by salivary glands $s^{49}$.

The molecular cloning and characterization of NIS allowed the identification of several NIS gene mutations in patients with iodide trapping defects ${ }^{50}$. Congenital iodide transport defects, therefore, represent the first group of thyroid diseases that is conclusively caused by a disorder of NIS (Figure 3). Only 9 months after cloning of hNIS, a first homozygous NIS gene mutation was reported by Fujiwara et al. in a Japanese patient, born to consanguinous parents, who presented with congenital hypothyroidism caused by an iodide transport defect. This patient's DNA included a single base alteration of ade- 


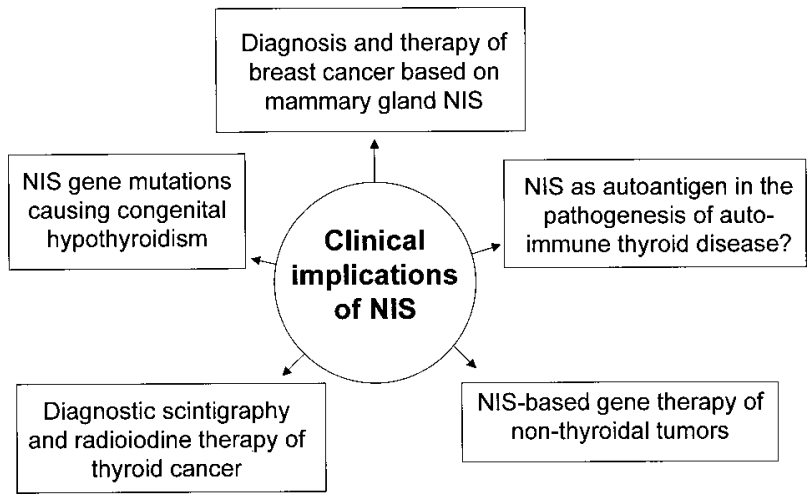

Figure 3. Clinical implications of NIS

nine to cytosine in codon 354 of the NIS gene which resulted in an exchange of threonine to proline (T354P $)^{51}$. Expression of the mutated symporter in vitro revealed complete loss of iodide transport activity, confirming the pathogenic role of this mutation. The same homozygous single base mutation in the ninth transmembrane domain of the NIS protein was identified in another Japanese patient with a voluminous diffuse goiter and an iodide accumulation defect ${ }^{52}$. Since then the T354P mutation has been demonstrated in 14 Japanese patients with an iodide trapping defect, demonstrating a high prevalence of the T354P mutation in Japanese patients ${ }^{51-56}$. NIS protein has been shown to be overexpressed in these patients' thyroid glands, suggesting compensatory overexpression of a hypo- or non-functioning NIS gene product ${ }^{54}$. In one familial case, three affected siblings were heterozygous for the T354P mutation. As the T354P mutation is a recessive mutation and causes iodide transport defect only in the homozygous or compound heterozygous state, another NIS gene mutation was considered to be present

Table 1. Identified and characterized mutations of the sodium iodide symporter gene

\begin{tabular}{lcc}
\hline Mutation & Result & Reference \\
\hline T354P & non-functioning NIS protein & $51-56$ \\
Q267E & non-functioning NIS protein & 58 \\
Y531X & 67 nt. deletion, frameshift, & \\
S515X & premature stop, truncated NIS protein & 58 \\
C272X & premature stop & \\
& truncated NIS protein & 59 \\
G93R & non-functioning NIS protein & 54 \\
G543E & non-functioning NIS protein & 54 \\
G395R & non-functioning NIS protein & 60 \\
V59E & non-functioning NIS protein & 57 \\
\hline
\end{tabular}

in these patients. PCR-directed sequencing of the NIS gene indeed revealed a single $\mathrm{T}$ to $\mathrm{A}$ transversion at the second base of the 59th codon in exon 1, thereby replacing the normal Val with $\mathrm{Glu}^{57}$ (Table 1).

Pohlenz et al. have reported three other NIS gene mutations. A patient with congenital hypothyroidism resulting from iodide trapping defect was shown to be heterozygous for two different mutations in the NIS gene $^{58}$ : a $\mathrm{C}$ to $\mathrm{G}$ transversion of nucleotide 1146 in exon 6, resulting in Gln 267 to Glu substitution; and a second $\mathrm{C}$ to $\mathrm{G}$ transversion of nucleotide 1940 , producing a stop codon as well as a downstream cryptic 3' splice acceptor site in exon 13, resulting in a 67 nucleotide deletion, frameshift, and premature stop ${ }^{58}$. In another patient with a large goiter and low thyroidal and salivary gland radioiodine uptake, sequencing of the entire NIS cDNA derived from thyroidal mRNA revealed a substitution of the normal cytosine in nucleotide 1163 with an adenine, resulting in a stop at codon 272 (exon 6) and expression of a truncated, nonfunctional form of NIS ${ }^{59}$. More recently, further loss-of-function mutations in the NIS gene (Gly 93 to Arg substitution, Gly 543 to Glu substitution, Gly 395 to Arg substitution) have been identified as a cause of iodide trapping defects ${ }^{54,60}$. Each of the above described NIS gene mutations showed a loss of iodide transport activity in transfection experiments and is of recessive nature (Table 1). Although resulting in an iodide trapping defect, the clinical pictures of the identified NIS gene mutations are very heterogenous, in particular concerning goiter formation and hypothyroidism. Patients with different NIS gene mutations as well as patients with an identical NIS gene mutation reveal different phenotypes suggesting that additional, unknown factors are responsible for variable clinical expression. While the precise mechanisms by which NIS gene mutations cause iodide trapping defects remain unknown, preliminary data suggest that conformational changes in the protein structure result in reduced functional activity and sodium binding capacity ${ }^{53}$. Very recently, using flow cytometry analysis and a mouse monoclonal antibody directed against the sixth extracellular loop of the hNIS protein, Pohlenz et al. were able to demonstrate that diminished membrane targeting is implicated in the mechanisms causing iodide trapping defects in the Q267E and S515X hNIS mutants ${ }^{61}$.

\section{The sodium iodide symporter as a novel autoantigen in autoimmune thyroid disease?}

The thyroid gland is the target of several autoimmune diseases, including Hashimoto's thyroiditis and Graves' hyperthyroidism. AITD is characterized by an immune 
response involving both cellular and humoral elements directed against thyroidal antigens. These autoantigens include TPO, Tg, and the TSH-receptor, proteins that are critical in thyroid cell function and hormonogenesis. As a newly recovered thyroidal membrane protein with an equally critical role in thyroid function, NIS and its potential role as a novel thyroid autoantigen in the pathogenesis of AITD has become the focus of many studies.

Even prior to the cloning of NIS, Raspe et al. reported inhibition of TSH-induced iodide uptake by cultured dog thyrocytes when exposed to serum of a patient with Hashimoto's thyroiditis (HT), autoimmune gastritis and rheumatoid arthritis. These authors hypothesized that cross-reacting NIS directed antibodies might be responsible for the decrease in iodide accumulating activity ${ }^{62}$. This early observation has gained support from data reported by Endo and colleagues, who expressed rat NIS (rNIS) as a glutathione S-transferase fusion protein, and examined a limited number of sera from patients with Graves' disease (GD) and HT for the presence of NIS antibodies. Employing a slot-blot assay and densitometric measurements, the authors reported that 22 of 26 $(84 \%)$ sera derived from patients with GD and 3 of 20 $(15 \%)$ sera from patients with HT contained $\mathrm{IgG}$ that bound to the NIS fusion protein ${ }^{63}$. Morris et al. employed a carefully calibrated ELISA system to examine IgG prepared from sera of patients with AITD for their binding to rNIS peptides. For this purpose, a series of 21 wellcharacterized rNIS peptides replicating the entire sequence of the 14 extramembranous domains of rNIS was generated. IgG were protein A affinity-purified from sera of 27 patients with GD, 27 patients with HT and 20 healthy controls. Binding of patient IgG significantly greater than normal $\mathrm{IgG}$ was observed to six peptides, representing the extramembranous domains $8,12,13$ and 14 of rNIS. Most notably, peptide 262-280 (extramembranous domain 8) and peptides 468-487 and 498-517 (both extramembranous domain 13) were recognized by $44 \%, 59 \%$ and $63 \%$ of GD IgG and by $15 \%, 11 \%$ and $26 \%$ of HT IgG, respectively, but by none of the control $\mathrm{IgG}^{64}$.

In addition to serving as markers of the underlying autoimmune response, more importantly NIS-directed antibodies may affect iodide uptake by the thyroid gland, thereby influencing thyroid function in patients with AITD. As reported by Endo et al., iodide transport inhibitory activity seemed to be present in IgG derived from patients with HT. Four of 34 sera obtained from patients with HT showed reactivity with recombinant rNIS by Western blot analysis. When tested in CHO-K1 cells sta- bly expressing rNIS, IgG prepared from these four patients were capable of inhibiting iodide uptake activity by 14 to $62 \%{ }^{65}$. Using $\mathrm{CHO}$ cells stably expressing a truncated form of hNIS, Ajjan et al. demonstrated that antibodies in GD sera possess iodide uptake inhibitory activity. 27 of $88(31 \%)$ sera derived from patients with GD inhibited iodide uptake more than $30 \%$. Purified IgG from some of the positive sera also suppressed iodide uptake, indicating that the effects of the patients' sera are mediated by antibodies ${ }^{66}$. However, because $\mathrm{CHO}$ cells stably transfected with a truncated form of human NIS that demonstrated only very low level of maximum iodide uptake were used in this assay, these data required confirmation by additional studies using more robust assays. Very recently the same group of investigators developed a specific and quantitative binding assay for the detection of NIS binding antibodies in sera from patients with AITD using in vitro transcription and translation followed by immunoprecipitation and RIA. Of 49 GD sera and 29 sera from patients with HT, 11 (22\%) and 7 (24\%), respectively, were found to contain NIS binding antibodies. In contrast, sera from 10 patients with Addison's disease and 10 patients with vitiligo were all negative. Eight of the $11(73 \%)$ GD sera and 3 of the 7 $(43 \%)$ HT sera, which tested positive for NIS antibodies in the immunoprecipitation assay, were also found to inhibit iodide uptake activity in CHO-K1 cells stably transfected with full-length hNIS cDNA. Although these data suggest that some NIS antibodies may indeed act to modulate thyroid function in patients with $\mathrm{HT}$ and, thus, play a role in the hypothyroidism of some patients with AITD, these results need to be confirmed in a larger series of serum samples ${ }^{67}$. Seissler et al. used a similar assay to detect NIS binding antibodies in a large series of sera from patients with GD $(n=177)$ and HT $(n=72)$ and healthy individuals $(n=165)$. Full-length hNIS was cloned from thyroid tissue, expressed by in vitro transcription and translation in the presence of [35S]methionine and used to detect NIS antibodies in a direct binding assay. In contrast to the study by Ajjan et al. using the 95.2th percentile of healthy controls as treshold, only 19 of 177 (10.7\%) patients with GD and 15 of 72 (20.8\%) patients with HT had detectable hNIS autoantibodies. Applying more stringent cut-off criteria (99.4th percentile of normal controls) hNIS antibodies were detected in only 5.6\% of GD sera and $6.9 \%$ of HT sera with significantly higher hNIS antibody levels in HT sera compared with sera from patients with GD and normal controls ${ }^{68}$. Using deletion derivatives of NIS cDNA, which were in vitro translated in the presence of [35S] methionine and immunoprecipitated with seven GD and six HT sera, that have 
been tested positive for NIS-binding antibodies, antibody binding sites of the hNIS protein could be identified (aa 1-134, 191-286, 290-411, 411-520, 520-588). No correlation between specific epitopes on the hNIS protein and the type of autoimmune thyroid disease was demonstrat$\mathrm{ed}^{69}$.

To further evaluate the functional activity of NIS binding antibodies in sera from patients with AITD, Chin et al. established a COS 7 cell line stably expressing high levels of functional hNIS protein which allowed to screen a large series of serum samples from normal subjects $(\mathrm{n}=33)$ and patients with AITD (GD $n=256, \mathrm{HT} n=43)$, non-AITD $(n=110)$, and non-thyroid autoimmune diseases $(n=67)$ for iodide uptake inhibiting activity. Only 14 sera revealed a significant decrease of iodide uptake activity compared with control sera. IgGs purified from seven of these 14 sera that were available for further study, did not reveal iodide uptake inhibiting activity indicating that the effects were not antibody mediated but caused by unknown serum factors ${ }^{70}$.

Taken together, while there is evidence that NIS directed antibodies are present in sera from patients with AITD, the biologic effect of anti-NIS autoantibodies remains in question. The simple presence of antibodies against NIS, does not, in itself, mandate a pathogenic role in the immune process. It may serve as a marker of the presence of autoimmune disease and be a consequence of cellular and follicular disruption and protein degradation rather than an active participant in the disease. The measurement of NIS antibodies with currently available assay systems does not offer any additional diagnostic benefit to detect patients with AITD. The clinical and pathogenic importance of NIS as a potential thyroid autoantigen in AITD therefore still remains to be determined in further studies.

\section{Mammary gland NIS and its clinical implications}

NIS mRNA and protein expression has been reported in a variety of extrathyroidal tissues, including salivary and lacrimal glands, gastric mucosa, kidney, placenta and mammary gland suggesting that iodide transport in these tissues is mediated by the expression of functional NIS protein ${ }^{39,71-74}$. In the lactating mammary gland iodide is actively transported and secreted into the milk, thereby supplying iodide to the infant for the biosynthesis of thyroid hormones which are essential for the development of the nervous system, skeletal muscle and lung ${ }^{1}$ (Figure 3).

In addition, a role for iodine in the prevention of breast dysplasia and hyperplasia has been suggested ${ }^{75-77}$. In a recent study, Kilbane et al. demonstrated that the tissue iodide content of breast carcinomas was significantly lower than that in remote normal tissue from the tumor-bearing breast or in fibroadenomata. It has therefore been proposed that a disorder of iodide uptake may be involved in the development of breast cancer which might be due to NIS inhibiting antibodies that are present in $19.6 \%$ of sera from breast carcinoma patients ${ }^{78}$ (Figure 3 ).

Very recently, the group led by Dr. Carrasco identified the mammary gland NIS (MGNIS) protein and demonstrated that it mediates iodide accumulation in lactating mammary glands ${ }^{74}$. By Western blot analysis using a high-affinity antibody directed against the carboxy-terminus of rat NIS, MGNIS was detected as a single band of approximately $75 \mathrm{kDa}$ in mammary gland membranes of lactating rats. Immunohistochemical analysis of paraffin-embedded tissue sections derived from lactating mammary gland showed distinct MGNIS-specific immunoreactivity at the basolateral membrane of alveolar epithelial cells ${ }^{74}$. Examination of MGNIS protein expression at various physiological stages showed that MGNIS is exclusively present in the mammary gland during gestation and lactation, in contrast to the constitutive expression of NIS in the thyroid gland. MGNIS was absent in nubile mammary glands, but present in lactating mammary glands. Twenty-four hours after mice were weaned MGNIS protein expression was substantially decreased, and was undetectable by $48 \mathrm{~h}$. Re-initiation of suckling re-established MGNIS expression ${ }^{74}$. These data suggest that hormones involved in active lactation stimulate MGNIS expression and/or its functional activity. Hormonal regulation studies in intact and ovariectomized mice showed rather complicated regulation mechanisms for MGNIS by estrogen, prolactin and oxytocin. A threshold level of circulating estrogens seemed to be necessary for optimal MGNIS expression in lactating mammary gland tissue, in particular for the upregulation of MGNIS by oxytocin. A combination of estrogens, prolactin and oxytocin, which resembles the relative hormonal levels in mice during lactation, led to the highest levels of MGNIS expression in ovariectomized mice ${ }^{74}$. In accordance with these findings, Cho et al. showed that both NIS protein expression levels and radioiodine uptake in rat mammary gland are maximal during active lactation compared to those in mammary glands of virgin and pregnant rats and in the involuting mammary gland. Radioiodine uptake into lactating mammary glands was partially inhibited by treatment with a selective oxytocin antagonist or bromocriptine, an inhibitor of prolactin 
release, suggesting that radioiodine uptake in the mammary gland is, at least in part, modulated by oxytocin and prolactin. In addition, using real-time quantitative RTPCR NIS mRNA levels have been shown to be increased in a dose-dependent manner by oxytocin and prolactin in three-dimensional histocultured human breast tumors $^{79}$. Furthermore, prolactin stimulation of iodide uptake by cultured mouse mammary tissues taken from pregnant mice had already been reported even before NIS was cloned, and has recently been shown to be due to increased NIS protein expression ${ }^{80-82}$.

The iodide concentrating activity of the thyroid gland allows the use of radioiodine for diagnosis of thyroid nodules by thyroid scintigraphy, as well as ablation of postsurgical remnants and treatment of recurrent and metastatic disease in thyroid cancer. The detection and characterization of MGNIS suggests that radioiodine might serve a similar function in the diagnosis and treatment of breast cancer (Figure 3). While normal mammary gland epithelial cells express MGNIS physiologically only during late gestation and lactation, Tazebay et al. ${ }^{32}$ demonstrated functional expression of MGNIS in experimental mammary adenocarcinomas in non-gestational and non-lactating female transgenic mouse models carrying either an activated Ras oncogene (c-Ha-ras) or overexpressing the Neu oncogene (c-erbB-2) by scintigraphic imaging and immunoblot analysis. Furthermore, using three polyclonal and monoclonal antibodies directed against different portions of the human NIS protein, MGNIS protein expression was examined in human breast tissue specimens including 8 normal specimens from reductive mammoplasties, 29 malignant specimens (23 invasive carcinomas, 6 ductal carcinomas in situ), 13 extratumoral specimens, and 3 biopsies from pregnant women with breast nodules. Twenty of the 23 $(87 \%)$ invasive carcinomas and 5 of the $6(83 \%)$ ductal carcinomas in situ were found to express MGNIS, compared with only 3 of the 13 (23\%) extratumoral specimens from tissue in the vicinity of the tumors. In addition, none of the 8 normal samples expressed MGNIS, while all three gestational samples were MGNIS-positive. In contrast to the distinct MGNIS-specific immunoreactivity at the basolateral membrane of epithelial cells in lactating mammary gland, in malignant breast cells MGNIS-positive staining was localized both at the plasma membrane and intracellularly ${ }^{74}$. The high prevalence of MGNIS in human breast cancer (more than $80 \%$ ) indicates that MGNIS is upregulated with high frequency during malignant transformation in human breast tissue and, therefore, has potential diagnostic value (Figure 3). Demonstration of functional activity of MGNIS protein expressed in breast cancer tissue in two different transgenic mouse models further suggests that radioiodine may be a possible alternative diagnostic and therapeutic modality in breast cancer (Figure 3).

A recent report by Kogai et al. shows induction of NIS gene expression and radioiodine uptake in breast cancer cells following treatment with retinoic acid (RA) ${ }^{83}$. RA plays a well characterized role in development, differentiation and cell growth and may have a role in the treatment of a number of cancer types by inhibiting cell cycle progression and induction of apoptosis. In addition, RA has been shown to upregulate NIS mRNA expression in human follicular thyroid carcinoma cell lines ${ }^{45}$. In the estrogen-receptor (ER)-positive human breast cancer cell line MCF-7 all-trans retinoic (tRA) acid treatment stimulated iodide uptake in a time- and dose-dependent fashion up to approximately 9.4-fold. Stimulation with selective retinoid compounds indicated that induction of iodide uptake is mediated by the retinoic acid receptor, which is expressed in MCF-7 cells. In addition, treatment with tRA significantly stimulated NIS mRNA as well as NIS protein expression. In contrast, no induction of iodide uptake was observed following RA treatment of the ER-negative human breast cancer cell line MDA-MB 231, or the normal human breast cell line MCF-12A. The absence of stimulation of iodide uptake after RA-treatment of several other human cancer cell lines, including prostate cancer cells (LNCaP), choriocarcinoma cells (JEG-3) and lung cancer cells (A549, H460), showed that the iodide uptakestimulating effect of RA was cell selective. Although no iodide organification could be detected in tRA-treated MCF-7 cells, iodide efflux was slow compared to iodide efflux in FRTL-5 thyroid cells, which may be the result of the absence of pendrin in MCF-7 cells. Most importantly, an in vitro clonogenic assay demonstrated selective cytotoxicity of ${ }^{131} \mathrm{I}$ in MCF-7 cells following tRA treatment $^{83}$. If these results can be confirmed in vivo, stimulation of radioiodine uptake by systemic retinoid treatment may have a role in imaging as well as therapy of breast cancer (Figure 3).

\section{NIS as a novel therapeutic gene}

Cloning of the NIS gene further allows the development of a novel cytoreductive gene therapy strategy based on targeted NIS gene transfer into non-thyroid cancer cells followed by radioiodine therapy. Early studies in transformed rat thyroid cells (FRTL-Tc) without iodide transport activity showed that transfection with rat NIS cDNA using electroporation is able to restore radioiodine accumulation in vitro and in vivo ${ }^{84}$. More recently, 
stable transfection of a NIS-defective follicular thyroid carcinoma cell line with the hNIS gene was able to reestablish iodide accumulation activity in vitro and in vivo ${ }^{85}$. Expression of functionally active NIS has also been reported in human glioma cells in vitro and in vivo using adenovirus-mediated NIS gene delivery ${ }^{86}$. Furthermore, Mandell et al. demonstrated in vitro and in vivo iodide accumulation in several cancer cell lines, including melanoma, liver, colon and ovarian carcinoma cells, following retrovirus-mediated transfection with the rat NIS gene. An in vitro clonogenic assay was used to demonstrate that rat NIS-transduced cancer cell lines can be selectively killed by the accumulated ${ }^{131} I^{87}$. Similar results were obtained by Boland et al., who expressed the rat NIS gene in several tumor cell lines (cervix, prostate, breast, lung and colon carcinoma cells) by adenovirusmediated gene transfer in vitro and demonstrated radioiodide uptake as well as a selective cytotoxic effect of trapped radioiodide in vitro. In cervix and breast cancer xenografts radioiodide uptake could also be demonstrated following in vivo NIS gene delivery. Intraperitoneal application of therapeutic doses of only up to $90 \mu \mathrm{mCi}$ ${ }^{131} \mathrm{I}$ did not result in a therapeutic response ${ }^{88}$. In a more recent study Nakamato et al. stably transfected a human breast cancer cell line with the rat NIS gene using electroporation and demonstrated a 44-fold increase in radioiodide uptake in vitro. Xenografts in athymic nude mice accumulated $16.7 \%$ of the total $125-$ I dose ${ }^{89}$. Following transfection with hNIS cDNA Carlin et al. showed radioiodine uptake activity in human glioma, neuroblastoma and ovarian adenocarcinoma cell lines. The selective cytotoxic effect of ${ }^{131} \mathrm{I}$ was significantly increased in three-dimensional spheroid cultures of hNIS-transfected human glioma cells compared with hNIS-transfected two-dimensional monolayer cultures indicating a substantial radiological bystander effect ${ }^{90}$. Using a bicistronic retroviral vector for hNIS gene transfer, Haberkorn et al. were able to demonstrate induction of radioiodide accumulation with a rapid iodide efflux in rat hepatoma cells in vitro and in vivo ${ }^{91}$. These data demonstrate the potential of NIS gene transfer to induce iodide accumulation activity in tumor cells, although the therapeutic efficacy of accumulated radioiodine remains to be confirmed in vivo.

Recently, prostate cancer (LNCaP) cells were shown to be selectively killed by accumulated ${ }^{131} \mathrm{I}$ following induction of tissue-specific iodide uptake activity by prostate-specific antigen (PSA) promoter-directed NIS expression in vitro ${ }^{92,93}$. Iodide accumulation was confirmed in vivo in $\mathrm{LNCaP}$ cell xenografts in athymic nude mice and was high enough to allow a therapeutic effect of ${ }^{131} \mathrm{I}$ in vivo. A single therapeutic ${ }^{131} \mathrm{I}$ dose of $3 \mathrm{mCi}$ was administered and shown to elicit a dramatic therapeutic response in NIS-transfected LNCaP cell xenografts with an average volume reduction of more than $90 \%{ }^{92}$. As a next crucial step towards therapeutic application of NIS gene delivery followed by radioiodine therapy in prostate cancer patients in a clinical setting, a replicationdeficient human adenovirus carrying the human NIS gene linked to the CMV promoter (Ad5-CMV-NIS) was used to perform in vivo NIS gene transfer into LNCaP cell tumors. Following intraperitoneal injection of a single therapeutic dose of $3 \mathrm{mCi}^{131} \mathrm{I}$ four days after adenovirus-mediated intratumoral NIS gene delivery, LNCaP xenografts showed a clear therapeutic response with an average volume reduction of more than $80 \%$. These studies clearly show for the first time that NIS gene delivery into non-thyroidal non-organifying tumor cells is capable of inducing accumulation of therapeutically effective radioiodine doses, and might therefore represent an effective and potentially curative therapy for extrathyroidal tumors, in particular prostate cancer (Figure 3).

\section{REFERENCES}

1. Carrasco N, 1993 Iodide transport in the thyroid gland. Biochem Biophys Acta 1154: 65-82.

2. Dai G, Levy O, Carrasco N, 1996 Cloning and characterization of the thyroid iodide transporter. Nature 379: 458460.

3. Smanik PA, Liu Q, Furminger TL, et al, 1996 Cloning of the human sodium iodide symporter. Biochem Biophys Res Commun 226: 339-345.

4. Bidart J-M, Mian C, Lazar V, et al, 2000 Expression of pendrin and the pendred syndrome (PDS) gene in human thyroid tissues. J Clin Endocrinol Metab 85: 20282033.

5. Everett LA, Glaser B, Beck JC, et al, 1997 Pendred syndrome is caused by mutations in a putative sulphate transporter gene (PDS). Nat Genet 17: 411-422.

6. Kopp P, 1999 Pendred's syndrome: Identification of the genetic defect a century after its recognition. Thyroid 9: 65-69.

7. Scott DA, Wang R, Kreman TM, Sheffield VC, Karniski LP, 1999 The Pendred syndrome gene encodes a chloride-iodide transport protein. Nat Genet 21: 440-443.

8. Royaux I, Suzuki K, Mori A, et al, 2000 Pendrin, the protein encoded by the Pendred syndrome gene (PDS), is an apical porter of iodide in the thyroid and is regulated by thyroglobulin in FRTL-5 cells. Endocrinology 141: 839845.

9. Smanik PA, Ryu K-Y, Theil KS, Mazzaferri EL, Jhiang SM, 1997 Expression, exon-intron organization, and chromosome mapping of the human sodium iodide symporter. Endocrinology 138: 3555-3558.

10. Levy O, De la Vieja A, Carrasco N, 1998 The Na+/I- sym- 
porter (NIS): Recent advances. J Bioenerg Biomemb 30: 195-206.

11. Kogai T, Endo T, Saito T, Miyazaki A, Kawaguchi A, Onaya T, 1997 Regulation of thyroid-stimulating hormone of sodium/iodide symporter gene expression and protein levels in FRTL-5 cells. Endocrinology 138: 2227-2232.

12. Saito T, Endo T, Kawaguchi A, et al, 1997 Increased expression of the $\mathrm{Na}+/ \mathrm{I}$ - symporter in cultured human thyroid cells exposed to thyrotropin and in Graves' thyroid tissue. J Clin Endocrinol Metab 82: 3331-3336.

13. Levy O, Dai G, Riedel C, et al, 1997 Characterization of the thyroid $\mathrm{Na}+/ \mathrm{I}-$ symporter with an anti-COOH terminus antibody. Proc Natl Acad Sci USA 94: 5568-5573.

14. Kogai T, Curcio F, Hyman S, Cornford EM, Brent GA, Hershman JM, 2000 Induction of follicle formation in long-term cultured normal human thyroid cells treated with thyrotropin stimulates iodide uptake but not sodium/iodide symporter messenger RNA and protein expression. J Endorinol 167: 125-135.

15. Riedel C, Levy O, Carrasco N, 2001 Post-transcriptional regulation of the sodium/iodide symporter (NIS) by thyrotropin. J Biol Chem 276: 21458-21463.

16. Harii N, Endo T, Ohmori M, Onaya T, 1999 Extracellular adenosine increases $\mathrm{Na}+/ \mathrm{I}$ - symporter gene expression in rat thyroid FRTL-5 cells. Mol Cell Endocrinol 157: 3139.

17. Kawaguchi A, Ikeda M, Endo T, Kogai T, Miyazaki A, Onaya T, 1997 Transforming growth factor- $\beta 1$ suppresses thyrotropin-induced $\mathrm{Na}+/ \mathrm{I}$ - symporter messenger RNA and protein levels in FRTL-5 rat thyroid cells. Thyroid 7: 789-794.

18. Pekary AE, Hershman JM, 1998 Tumor necrosis factor, ceramide, transforming growth factor-beta1, and aging reduce $\mathrm{Na}+/ \mathrm{I}$ - symporter messenger ribonucleic acid levels in FRTL-5 cells. Endocrinology 139: 703-712.

19. Ajjan RA, Kamaruddin NA, Crisp M, Watson PF, Ludgate M, Weetman AP, 1998 Regulation and tissue distribution of the human sodium iodide symporter gene. Clin Endocrinol 49: 517-523.

20. Ajjan RA, Watson PF, Findlay C, et al, 1998 The sodium iodide symporter gene and its regulation by cytokines found in autoimmunity. J Endocrinol 158: 351-358.

21. Spitzweg C, Joba W, Morris JC, Heufelder AE, 1999 Regulation of sodium-iodide symporter gene expression in FRTL-5 rat thyroid cells. Thyroid 9: 821-830.

22. Suzuki K, Mori A, Saito J, Moriyama E, Ullianich L, Kohn LD, 1999 Follicular thyroglobulin suppresses iodide uptake by suppressing expression of the sodium/iodide symporter gene. Endocrinology 140: 5422-5430.

23. Furlanetto TW, Nguyen LQ, Jameson JL, 1999 Estradiol increases proliferation and down-regulates the sodium/ iodide symporter gene in FRTL-5 cells. Endocrinology 140: 5705-5711.

24. Wolff J, Chaikoff IL, 1948 Plasma inorganic iodide as a homeostatic regulator of thyroid function. J Biol Chem 174: 555-564.

25. Wolff J, Chaikoff IL, Goldberg RC, Meier JR, 1949 The temporary nature of the inhibitory action of excess io- dide on organic iodine synthesis in the normal thyroid. Endocrinology 45: 504-513.

26. Uyttersprot N, Pelgrims N, Carrasco N, et al, 1997 Moderate doses of iodide in vivo inhibit cell proliferation and the expression of thyroperoxidase and $\mathrm{Na}+/ \mathrm{I}-$ symporter mRNAs in dog thyroid. Mol Cell Endocrinol 131: 195203.

27. Eng PHK, Cardona GR, Fang S-L, et al, 1999 Escape from the acute Wolff-Chaikoff effect is associated with a decrease in thyroid sodium/iodide symporter messenger ribonucleic acid and protein. Endocrinology 140: 3404-3410.

28. Caillou B, Troalen F, Baudin E, et al, $1998 \mathrm{Na}+/ \mathrm{I}-$ symporter distribution in human thyroid tissues: An immunohistochemical study. J Clin Endocrinol Metab 83: 41024106.

29. Arturi F, Russo D, Schlumberger M, et al, 1998 Iodide symporter gene expression in human thyroid tumors. J Clin Endocrinol Metab 83: 2493-2496.

30. Castro MR, Bergert ER, Beito TG, et al, 1999 Monoclonal antibodies against the human sodium iodide symporter: Utility for immunocytochemistry of thyroid cancer. J Endocrinol 163: 495-504.

31. Castro MR, Bergert ER, Beito TG, McIver BD, Goellner JR, Morris JC, 1999 Development of monoclonal antibodies against the human sodium iodide symporter: Immunohistochemical characterization of this protein in thyroid cells. J Clin Endocrinol Metab 84: 2957-2962.

32. Saito T, Endo T, Kawaguchi A, et al, 1998 Increased expression of the sodium/iodide symporter in papillary thyroid carcinomas. J Clin Invest 101: 1296-1300.

33. Joba W, Spitzweg C, Schriever K, Heufelder AE, 1999 Analysis of human sodium/iodide symporter, thyroid transcription factor-1, and paired-box-protein-8 gene expression in benign thyroid diseases. Thyroid 9: 455-466.

34. Mazzaferri EL 1996 Carcinoma of follicular epithelium: Radioiodine and other treatments and outcomes. In: L.E. Braverman and RD Utiger (eds), The Thyroid: A Fundamental and Clinical Text, 7th edition. Philadelphia: Lippincott - Raven, pp. 922-945.

35. Mazzaferri EL, Jhiang SM, 1994 Long-term impact of initial surgical and medical therapy on papillary and follicular thyroid cancer. Am J Med 97: 418-28.

36. Lazar V, Bidart J-M, Caillou B, et al, 1999 Expression of the $\mathrm{Na}+/ \mathrm{I}-$ symporter gene in human thyroid tumors: a comparison study with other thyroid-specific genes. J Clin Endocrinol Metab 84: 3228-3234.

37. Park H-J, Kim JY, Park KY, Gong G, Hong SJ, Ahn I-M, 2000 Expressions of human sodium iodide symporter mRNA in primary and metastatic papillary thyroid carcinomas. Thyroid 10: 211-217.

38. Trapasso F, Iuliano R, Chiefari E, et al, 1999 Iodide symporter gene expression in normal and transformed rat thyroid cells. Eur J Endocrinol 140: 447-451.

39. Jhiang SM, Cho J-Y, Ryu K-Y, et al, 1998 An immunohistochemical study of $\mathrm{Na}+$ /I- symporter in human thyroid tissues and salivary gland tissues. Endocrinology 139:4416-4419.

40. Min J-J, Chung J-K, Lee YJ, et al, 2001 Relationship be- 
tween expression of the sodium/iodide symporter and 131I uptake in recurrent lesions of differentiated thyroid carcinoma. Eur J Nucl Med 28: 639-645.

41. Castro MR, Bergert ER, Goellner JR, Hay ID, Morris JC, 2001 Immunohistochemical analysis of sodium iodide symporter expression in metastatic differentiated thyroid cancer: correlation with radioiodine uptake. J Clin Endocrinol Metab 86: 5121-5632.

42. Russo D, Manole D, Arturi F, et al, 2001 Absence of sodium/iodide symporter gene mutations in differentiated human thyroid carcinomas. Thyroid 11: 37-39.

43. Kogai T, Hershman JM, Motomura K, Endo T, Onaya T, Brent GA, 2001 Differential regulation of the human sodium/iodide symporter gene promoter in papillary thyroid carcinoma lines and normal thyroid cells. Endocrinology 142: 3369-3379.

44. Dohan O, Baloch Z, Banrevi Z, Livolsi V, Carrasco N, 2001 Predominant intracellular overexpression of the $\mathrm{Na}+/ \mathrm{I}-$ symporter (NIS) in a large sampling of thyroid cancer cases. J Clin Endocrinol Metab 86: 2697-2700.

45. Schmutzler C, Winzer R, Meissner-Weigl J, Kohrle J, 1997 Retinoic acid increases sodium/iodide symporter mRNA levels in human thyroid cancer cell lines and suppresses expression of functional symporter in nontransformed FRTL-5 rat thyroid cells. Biochem Biophys Res Commun 240: 832-838.

46. Simon D, Koehrle J, Reiners C, et al, 1998 Redifferentiation therapy with retinoids: therapeutic option for advanced follicular and paillary carcinoma. World J Surg 22: $569-574$

47. Venkataraman GM, Yatin M, Marcinek R, Ain KB, 1999 Restoration of iodide uptake in dedifferentiated thyroid carcinoma: Relationship to human $\mathrm{Na}+/ \mathrm{I}$ - symporter gene methylation status. J Clin Endocrinol Metab 84: 2449-2457.

48. Kitazono M, Robey R, Zhan Z, et al, 2001 Low concentrations of the histone deacetylase inhibitor, depsipeptide (FR901228), increase expression of the $\mathrm{Na}(+) / \mathrm{I}(-)$ symporter and iodine accumulation in poorly differentiated thyroid carcinoma cells. J Clin Endocrinol Metab 86: 3430-3435.

49. Stanbury JB, Dumont JE, 1983 Familial goiter and related disorders. McGraw-Hill, New York, p. 231-269.

50. Pohlenz J, Refetoff S, 1999 Mutations in the sodium/iodide symporter (NIS) gene as a cause for iodide transport defects and congenital hypothyroidism. Biochimie 81: 469-476.

51. Fujiwara H, Tatsumi K-I, Miki K, et al, 1997 Congenital hypothyroidism caused by a mutation in the $\mathrm{Na}+$ /I- symporter. Nat Genet 16: 124-125.

52. Matsuda A, Kosugi S, 1997 A homozygous missense mutation of the sodium/iodide symporter gene causing iodide transport defect. J Clin Endocrinol Metab 82: $3966-$ 3971.

53. Tatsumi K-I, Miyai K, Amino N, 1998 Genetic basis of congenital hypothyroidism: abnormalities in the TSH $\beta 1$ gene, the PIT1 gene, and the NIS gene. Clin Chem Lab Med 36: 659-662.
54. Kosugi S, Inoue S, Matsuda A, Jhiang SM, 1998 Novel, missense and loss-of-function mutations in the sodium/ iodide symporter gene causing iodide transport defect in three Japanese patients. J Clin Endocrinol Metab 83: 3373-3376.

55. Kosugi S, Sato Y, Matsuda A, et al, 1998 High prevalence of T354P sodium/iodide symporter gene mutation in Japanese patients with iodide transport defect who have heterogeneous clinical pictures. J Clin Endocrinol Metab 83: 4123-4129.

56. Fujiwara H, Tatsumi K-I, Miki K, et al, 1998 Recurrent T354P mutation of the $\mathrm{Na}+/ \mathrm{I}$ - symporter in patients with iodide transport defect. J Clin Endocrinol Metab 83: 29402943.

57. Fujiwara H, Tatsumi K, Tanaka S, Kimura M, Nose O, Amino N, 2000 A novel V59E missense mutation in the sodium iodide symporter gene in a familiy with iodide transport defect. Thyroid 10: 471-474.

58. Pohlenz J, Rosenthal IM, Weiss RE, Jhiang SM, Burant C, Refetoff S, 1998 Congenital hypothyroidism due to mutations in the sodium/iodide symporter. Identification of a nonsense mutation producing a downstream cryptic 3 ' splice site. J Clin Invest 101: 1028-1035.

59. Pohlenz J, Mederios-Neto G, Gross JL, Silveiro SP, Knobel M, Refetoff S, 1997 Hypothyroidism in a Brazilian kindred due to iodide trapping defect caused by a homozygous mutation in the sodium/iodide symporter gene. Biochem Biophys Res Commun 240: 488-491.

60. Kosugi S, Bhayana S, Dean HJ, 1999 A novel mutation in the sodium/iodide symporter gene in the largest family with iodide transport defect. J Clin Endocrinol Metab 84: 3248-3253.

61. Pohlenz J, Duprez L, Weiss R, Vassart G, Refetoff S, Costagliola S, 2000 Failure of membrane targeting causes the functional defect of two mutant sodium iodide symporters. J Clin Endocrinol Metab 85: 2366-2369.

62. Raspe E, Costagliola S, Ruf J, Mariotti S, Dumont JE, Ludgate M, 1995 Identification of the thyroid $\mathrm{Na}+/ \mathrm{I}-$ cotransporter as a potential autoantigen in thyroid autoimmune disease. Eur J Endocrinol 132: 399-405.

63. Endo T, Kogai T, Nakazato M, Saito T, Kaneshige M, Onaya T, 1996 Autoantibody against Na+/I- symporter in the sera of patients with autoimmune thyroid disease. Biochem Biophys Res Commun 224: 92-95.

64. Morris JC, Bergert ER, Bryant WP, 1997 Binding of IgG from patients with autoimmune thyroid disease to rat sodium-iodide symporter peptides: Evidence for the iodide transporter as an autoantigen. Thyroid 7: 527-534.

65. Endo T, Kaneshige M, Nakazato M, Kogai T, Saito T, Onaya T, 1996 Autoantibody against thyroid iodide transporter in the sera from patients with Hashimoto's thyroiditis possesses iodide transport inhibitory activity. Biochem Biophys Res Commun 228: 199-202.

66. Ajjan RA, Findlay C, Metcalfe RA, et al, 1998 The modulation of the human sodium iodide symporter activity by Graves' disease sera. J Clin Endocrinol Metab 83:12171221.

67. Ajjan RA, Kemp EH, Waterman E, et al, 2000 Detection 
of binding and blocking autoantibodies to the human sodium-iodide symporter in patients with autoimmune thyroid disease. J Clin Endocrinol Metab 85: 2020-2027.

68. Seissler J, Wagner S, Schott M, et al, 2000 Low frequency of autoantibodies to the human $\mathrm{Na}+/ \mathrm{I}-$ symporter in patients with autoimmune thyroid disease. J Clin Endocrinol Metab 85: 4630-4634.

69. Kemp EH, Waterman EA, Ajjan RA, et al, 2001 Identification of antigenic domains on the human sodium-iodide symporter which are recognized by autoantibodies from patients with autoimmune thyroid disease. Clin Exp Immunol 124: 377-385.

70. Chin HS, Chin DKH, Morgenthaler NG, Vassart G, Costagliola S, 2000 Rarity of anti-Na+/I- symporter (NIS) antibody with iodid uptake inhibiting activity in autoimmune thyroid disease (AITD). J Clin Endocrinol Metab 85: 3937-3940.

71. Spitzweg C, Joba W, Schriever K, Goellner JR, Morris JC, Heufelder AE, 1999 Analysis of human sodium iodide symporter immunoreactivity in human exocrine glands. J Clin Endocrinol Metab 84: 4178-4184.

72. Spitzweg C, Joba W, Eisenmenger W, Heufelder AE, 1998 Analysis of human sodium iodide symporter gene expression in extrathyroidal tissues and cloning of its complementary deoxyribonucleic acids from salivary gland, mammary gland, and gastric mucosa. J Clin Endocrinol Metab 83: 1746-1751.

73. Spitzweg C, Dutton CM, Castro MR, et al, 2001 Expression of the sodium iodide symporter in human kidney. Kidney Int 59:1013-1023.

74. Tazebay UH, Wapnir IL, Levy O, et al, 2000 The mammary gland iodide transporter is expressed during lactation and in breast cancer. Nat Med 6: 871-878.

75. Eskin BA, 1970 Iodine metabolism and breast cancer. Trans NY Acad Sci 32: 911-947.

76. Eskin B, Bartuska D, MR D, Jacob G, Dratman MB, 1967 Mammary gland dysplasia in iodine deficiency. JAMA 200: 691-695.

77. Funahashi H, Imai T, Tanaka Y, et al, 1996 Suppressive effect of iodine on DMBA induced breast tumour growth in the rat. J Surg Oncol 61: 209-213.

78. Kilbane M, Ajjan R, Weetman A, et al, 2000 Tissue iodine content and serum-mediated 125I uptake-blocking activity in breast cancer. J Clin Endocrinol Metab 85: 12451250.

79. Cho J-Y, Leveille R, Kao R, et al, 2000 Hormonal regulation of radioiodide uptake activity and $\mathrm{Na}+/ \mathrm{I}$ - symporter expression in mammary glands. J Clin Endocrinol Metab 85: 2936-2943.

80. Rillema JA, Yu TX, 1996 Prolactin stimulation of iodide uptake into mouse mammary gland explants. Am J Physiol 271: E879-E882.
81. Rillema JA, Rowady DL, 1997 Characteristics of the prolactin stimulation of iodide uptake into mouse mammary gland explants. Proc Soc Exp Biol Med 215: 366-369.

82. Rillema JA, Yu TX, Jhiang SM, 2000 Effect of prolactin on sodium iodide symporter expression in mouse mammary gland explants. Am J Physiol Endocrinol Metab 279: E769-E772.

83. Kogai T, Schultz J, Johnson L, Huang M, Brent G, 2000 Retinoic acid induces sodium/iodide symporter gene expression and radioiodide uptake in the MCF-7 breast cancer cell line. Proc Natl Acad Sci, USA 97: 8519-8524.

84. Shimura H, Haraguchi K, Miyazaki A, Endo T, Onaya T, 1997 Iodide uptake and experimental ${ }^{131}$ I therapy in transplanted undifferentiated thyroid cancer cells expressing the $\mathrm{Na}+/ \mathrm{I}-$ symporter gene. Endocrinology 138: 44934496.

85. Smit JWA, Schroder-van der Elst JP, Karperien M, et al, 2000 Reestablishment of in vitro and in vivo iodide uptake by transfection of the human sodium iodide symporter (hNIS) in a hNIS defective human thyroid carcinoma cell line. Thyroid 10: 939-943.

86. Cho J-Y, Xing S, Liu X, et al, 2000 Expression and activity of human $\mathrm{Na}+/ \mathrm{I}-$ symporter in human glioma cells by adenovirus-mediated gene delivery. Gene Ther 7: 740-749.

87. Mandell RB, Mandell LZ, Link CJ, 1999 Radioisotope concentrator gene therapy using the sodium/iodide symporter gene. Cancer Res 59: 661-668.

88. Boland A, Ricard M, Opolon P, et al, 2000 Adenovirusmediated transfer of the thyroid sodium/iodide symporter gene into tumors for a targeted radiotherapy. Cancer Res 60: 3484-3492.

89. Nakamato Y, Saga T, Misaki T, et al, 2000 Establishment and characterization of a breast cancer cell line expressing $\mathrm{Na}+/ \mathrm{I}-$ symporters for radioiodide concentrator gene therapy. J Nucl Med 41: 1898-1904.

90. Carlin S, Cunningham SH, Boyd M, McCluskey AG, Mairs RJ, 2000 Experimental targeted radioiodide therapy following transfection of the sodium iodide symporter gene: effect on clonogenicity in both two- and three-dimensional models. Cancer Gene Therapy 7: 1529-1536.

91. Haberkorn U, Henze M, Altmann A, et al, 2001 Transfer of the human NaI symporter gene enhances iodide uptake in hepatoma cells. J Nucl Med 42: 317-325.

92. Spitzweg C, O'Connor MK, Bergert ER, Tindall DJ, Young CYF, Morris JC, 2000 Treatment of prostate cancer by radioiodine therapy after tissue-specific expression of the sodium iodide symporter. Cancer Res 60: 65266530.

93. Spitzweg C, Zhang S, Bergert ER, et al, 1999 Prostatespecific antigen (PSA) promoter-driven androgen-inducible expression of sodium iodide symporter in prostate cancer cell lines. Cancer Res 59: 2136-2141. 